\title{
Designing and Validation of a Sprocket Wheel for a Formula Student Vehicle
}

\author{
Rohan Rai, Sharat Anand, Shayak Choudhary, G Sashank, Saheb Singh Wadhwa, Devashish Roy, N K Samota \\ Department of Mechanical Engineering \\ KIIT Deemed to be University (Institute of Eminence), Bhubaneswar, India
}

\begin{abstract}
This report includes the overall design process and analysis parts of a part of the powertrain/drivetrain component of a vehicle called as a Sprocket. The process consists of designing a part using the accurate and precise CAD software followed by elimination of defects and optimization of the part. The validation of a part is carried out on the basis of analytical study performed by the CAE software. The part is a component manufactured for the Formula Student car of Team Hermes Racing of KIIT University. It has been designed to perform effortlessly in all the dynamic conditions and consists of the capability of being tuned manually to enhance the car's performance according to the requirements of a specific dynamic event. A 45 teeth Sprocket has been chosen here as per the requirements of the car.
\end{abstract}

Keywords- Sprocket, Formula Student, CAD, CAE, Billet, Pitch Circle Diameter.

\section{A. INTRODUCTION}

\subsection{Background}

A sprocket is a categorical type of wheel with multiple teeth/slots that can mesh with a chain and get attached with it. 'Sprocket', namely refers to a wheel of any type over which radially directed projections for engagement is made and a chain is passed over it. It is differentiated from a gear by the fact that it can never be meshed together directly and differs from a pulley as a sprocket has teeth. Sprockets find applications in bi-cycles, motorbikes, cars, tracking vehicles, and other machinery either to transmit rotational motion between two shafts where gears are unsuitable or used to impart linear motion for tracking, taping etc. Usually sprocket is found in bicycle, where the pedal shifter carries the large sprocket, which acts as driver of chain, furthers a driving sprocket of the rear wheel. Automobiles in the past largely used sprocket and chain mechanism. Sprockets bear various types of designs. Sprocket wheels and chain are typically used for transmission of power from one shaft to another from where a restriction of slippage is present. Sprockets are designed to bear heavy torque and resistance to fatigue load.

\subsection{Sprocket Billet}

A sprocket billet is used to support the sprocket and assemble it with the Driveshafts and the Differential used. It has drilled holes as per the pitch of the Sprocket. The holes of the sprocket billet must have the same number of drilled holes and the same pitch as that of the designed
Sprocket wheel. The Pitch Circle Diameter of the Billet should be made complimentary to the sprocket. The billet needs to have splines which can bear one of the ends of a Differential and the other end of a half-shaft. It can be manufactured using several materials as well as several Advance Manufacturing Techniques such as water-jet machining.

\subsection{Roller Chain}

Roller chain/Bush Roller Chain is a categorical part of chain drive mechanism used commonly for transmission purpose of mechanical power to versatile machineries, including conveyors belts, tube-wire machines, printing presses, automobiles, motor-cycles/bicycles. Short cylindrical roller cells compile up together to hold together by side links. A toothed wheel called sprocket is used to hold the chain and connected within the driven and driving Sprocket. It is meant for simple and hassle-free power transmission.

\subsection{Design and Performance Requirements}

The Sprocket has been designed as per the use and performance required by a Formula Student Vehicle. The preferred parameters are as follows-

- Vehicle Performance plays a major role in the dynamic conditions, thus the sprocket used here has been designed in such a manner that it can provide the maximum efficiency.

- The sprocket is designed to bear the load of a 390cubic capacity (cc) engine and 42 Brake Horse Power (BHP)

- The Sprocket needs to provide high acceleration to the vehicle along-with the maximum torque it can.

- The utmost optimization in the Sprocket is needed to be done so as to obtain maximum acceleration and higher Rotations per minute (RPM) of the wheel, thus providing higher speed to the car built.

\section{B. LITERATURE SURVEY}

Sprocket mainly interlinks with the differential and the drive chain. Size of the tooth count of the sprocket is the main factor influencing the acceleration of the car and transitions between the gears of the transmission during dynamic events. Sprocket is built to take the linear force of the drive chain and produce rotational energy from it to rotate the differential further connected to the wheels. Thus, the diameter of the sprocket helps to produce a moment arm to produce a torque on the differential. Here, 
a 45 teeth sprocket is considered because using such a sprocket will result in better start in the acceleration. The Main objectives during the designing of a sprocket are to make sprocket lighter and optimized for larger moment arm. Sprocket is the final element of the driveline where reduction occurs, so design of the sprocket should be such that the rate of acceleration and output torque should be decent and one should not be compromised for the other.

\subsection{Constraints \& Considerations}

2.1.1. Overall dimension should be compatible with the rear end packaging of the car.

2.1.2. The number of teeth defines the level of reduction hence deciding the output characteristics.

\subsection{Material Selection}

The sprocket is manufactured using Aluminium Alloy 7075 which is Tempered. Thus, bearing the grade of Aluminium T7. The composition of the alloy chosen is 5.6 $-6.1 \% \mathrm{Zn}, 2.1-2.5 \% \mathrm{Mg}, 1.2-1.6 \% \mathrm{Cu}$, and about $1 / 2$ percent of Iron, Silicon, Chromium, Titanium, Molybdenum and other metals. Some other tempers are 7070-T6, 7075-T651, 7074-0.

\subsubsection{Reasons for Using Aluminium 7075 Tempered Alloy}

The material is preferred due to its high physical strength, Fatigue strength, good machinability and light weight nature. Bears an elongation failure of $13 \%$. T7 tempering involves over-aging the material in raw state. Aging is done at $100-120^{\circ} \mathrm{C}$ for hours and then at $160-180^{\circ} \mathrm{C}$ for around $24 \mathrm{hrs}$. T7 tempering produces a micro-structure of mostly eta precipitates $\left(\mathrm{Ni}_{3} \mathrm{Ti}\right)$. As compared to temper T6, the precipitate particles of $\mathrm{T} 7$ are larger and oriented to growth. Thus, the susceptibility to stress corrosion cracking is reduced.

\subsubsection{Mechanical Properties}

TABLE 1: Material Properties

\begin{tabular}{|l|c|}
\hline \multicolumn{1}{|c|}{ PROPERTIES } & METRIC \\
\hline Tensile Strength & $510 \mathrm{MPa}$ \\
\hline Yield Strength & $410 \mathrm{MPa}$ \\
\hline Elasticity of Modulus & $70 \mathrm{GPa}$ \\
\hline Shear -Modulus & $26 \mathrm{GPa}$ \\
\hline Poisson's- Ratio & 0.32 \\
\hline
\end{tabular}

\section{CALCULATION}

Acceleration for sprocket with 45 teeth,

\section{Given:}

Torque $=35 \mathrm{Nm}$

$1^{\text {st }}$ gear ratio $=12 / 32$

Final drive ratio $=2.66 \times 2.66 \times(45 / 14)$
No. of teeth in driven sprocket $=45$

No. of teeth in driving sprocket $=14$

Assumed driveline efficiency $=60 \%=0.6$

Rolling radius of wheels $=0.228 \mathrm{~m}$

Vehicle gross weight $=220 \mathrm{~kg}$

- Acceleration Thrust =

Torque $x$ Final drive ratio $x$ Driveline efficiency (i) Rolling radius of wheels

$=\underline{35 \times 2.66 \times 2.66 \times 3 \times 0.6}=\mathbf{1 9 5 5 . 1} \mathrm{kg} \cdot \mathrm{m} / \mathbf{s}^{2}$ 228

- Acceleration Rate $=$

Acceleration Thrust

(ii)

Vehicle gross weight

$$
=\underline{19551}=8.88 \mathrm{~m} / \mathbf{s e c}^{2}
$$

\subsection{Design Alternatives}

\begin{tabular}{|c|c|}
\hline $\begin{array}{l}\text { NO. OF } \\
\text { TOOTH }\end{array}$ & $\begin{array}{c}\text { ACCELERATION } \\
\left(\mathrm{m} / \sec ^{\wedge} 2\right)\end{array}$ \\
\hline 35 & 6.91 \\
\hline 36 & 7.11 \\
\hline 37 & 7.31 \\
\hline 38 & 7.50 \\
\hline 39 & 7.70 \\
\hline 40 & 7.90 \\
\hline 41 & 8.10 \\
\hline 42 & 8.29 \\
\hline 43 & 8.49 \\
\hline 44 & 8.69 \\
\hline 45 & 8.89 \\
\hline 46 & 9.08 \\
\hline \multirow[t]{2}{*}{47} & 9.28 \\
\hline & 9.48 \\
\hline
\end{tabular}

TABLE 2: Acceleration on the basis of Number of Teeth 


\subsection{Design Determination of The Sprocket}

As per the formulas provided in the table (3), the values required for designing a Sprocket wheel are determined. The Chain used for reference is that of KTM RC-390 motorbike. The determined formula for the required values is as follows-

TABLE 3: Formulae for Designing of Sprocket

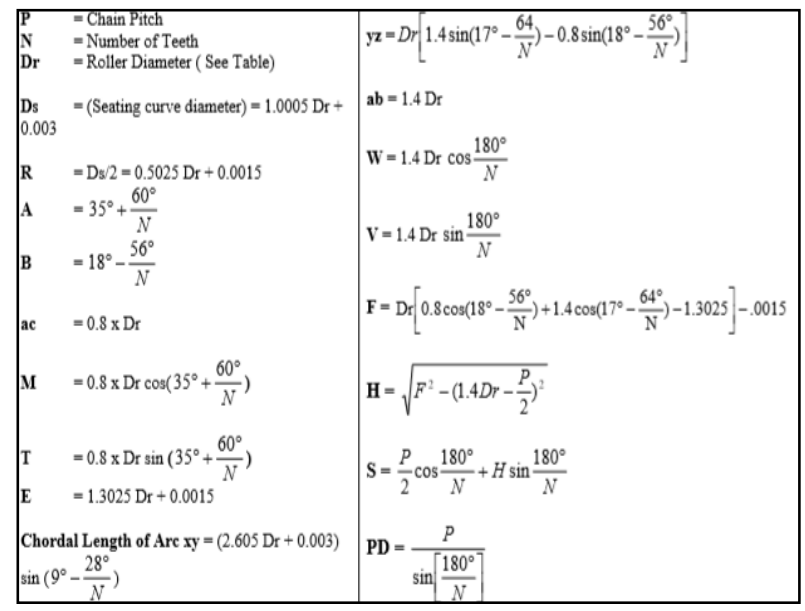

With the data from the table we can proceed forward for the step-wise designing of a sprocket

1.All the values required were derived as mentioned in table (3)

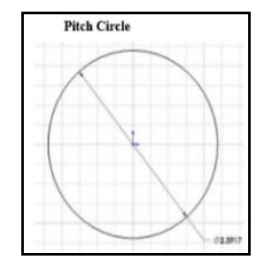

2.A Pitch Circle of radius $1 / 2$ of PD was drawn.

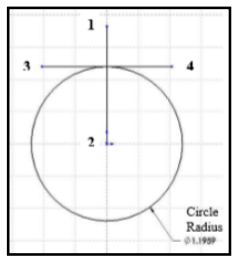

3. Construction line 1,2 was drawn from center of circle to Top Quadrant.

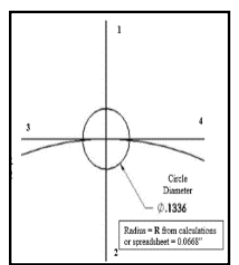

4.Horizontal line 3,4 was drawn from top quadrant and tangent to pitch circle was made.

5.A circle with radius $R$, at intersection of $1,2 \& 3,4$ was drawn.

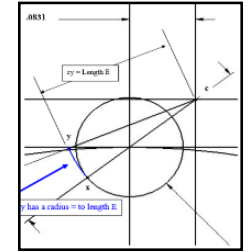

6.Offsetting the above lines was done.

7.Extending line cx was made

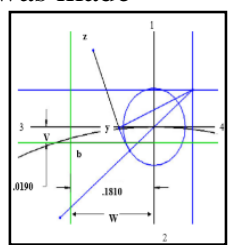

8.Line cy was drawn=E.

9.Draw arc xy and line segment yz.

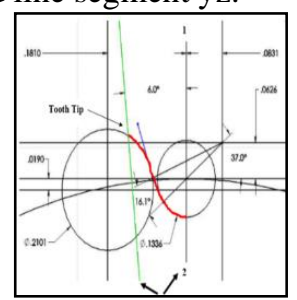

10.Locate offset point made above and make a new circle radius $F$.

11.Joining the tip of lines were made and required shape was given.

12.Follo up trimmings and others to get the proper shape. 13.Mirror of the above line and arc was done to get the desired drawing.

14.Array the Tooth with the pitch line of the wheel.

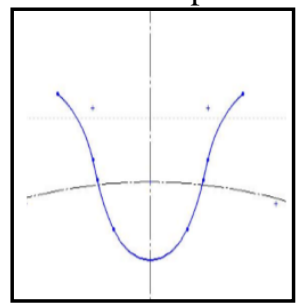

Here we have used 45 teeth, thus array it 45 times to get the required sprocket wheel.

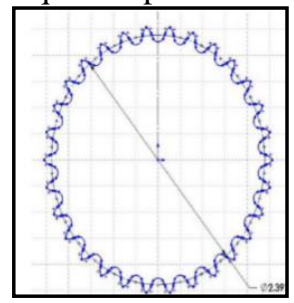

\section{RESULT}

A 45 teeth Sprocket wheel was thus designed using the previously mentioned steps and with the following values of data calculated- 
TABLE 4: Values of Parameters chosen in Table-3

\begin{tabular}{|l|l|}
\hline \multicolumn{2}{|c|}{ P= 15.88mm, $\mathbf{D}_{\mathbf{r}}=\mathbf{1 5 . 8 7} \mathbf{m m}, \mathbf{N}=\mathbf{4 5}$ teeth } \\
\hline $\mathrm{Ds}=15.88 \mathrm{~mm}$ & $\mathrm{xy}$ chord $=6.024$ \\
\hline $\mathrm{R}=7.943 \mathrm{~mm}$ & $\mathrm{yz}=2.306 \mathrm{~mm}$ \\
\hline $\mathrm{A}=36.33 \mathrm{~mm}$ & $\mathrm{ab}=22.218 \mathrm{~mm}$ \\
\hline $\mathrm{B}=16.75 \mathrm{~mm}$ & $\mathrm{~W}=22.1638 \mathrm{~mm}$ \\
\hline $\mathrm{a}=12.696 \mathrm{~mm}$ & $\mathrm{~V}=1.5498 \mathrm{~mm}$ \\
\hline $\mathrm{M}=10.228 \mathrm{~mm}$ & $\mathrm{~F}=12.87 \mathrm{~N}$ \\
\hline $\mathrm{T}=7.521 \mathrm{~mm}$ & $\mathrm{M}=19.21 \mathrm{~mm}$ \\
\hline $\mathrm{E}=20.67 \mathrm{~mm}$ & $\mathrm{~S}=9.26$ \\
\hline \multicolumn{2}{|c|}{$\mathbf{P D}=\mathbf{2 2 7 . 6 4} \mathbf{~ m m}$} \\
\hline
\end{tabular}

E. DESIGN VALIDATION

A design is ready to be applied practically, only if it is fit to undergo the various harsh stresses of nature. Thus, a proper Analysis of the designed product is required to be done to validate its application. This can be done using any CAE software under suitable parameters.

\subsection{Static Structure Analysis}

A static structure analysis of the sprocket is done validating the material used and even the design. Following constraints have been provided-

Total Force Applied- 30N, Maximum Torque applied at 6000 RPM

Maximum Deformation at Red Region $=0.01739 \mathrm{~mm}$,

Minimum Deformation $=0 \mathrm{~mm}$

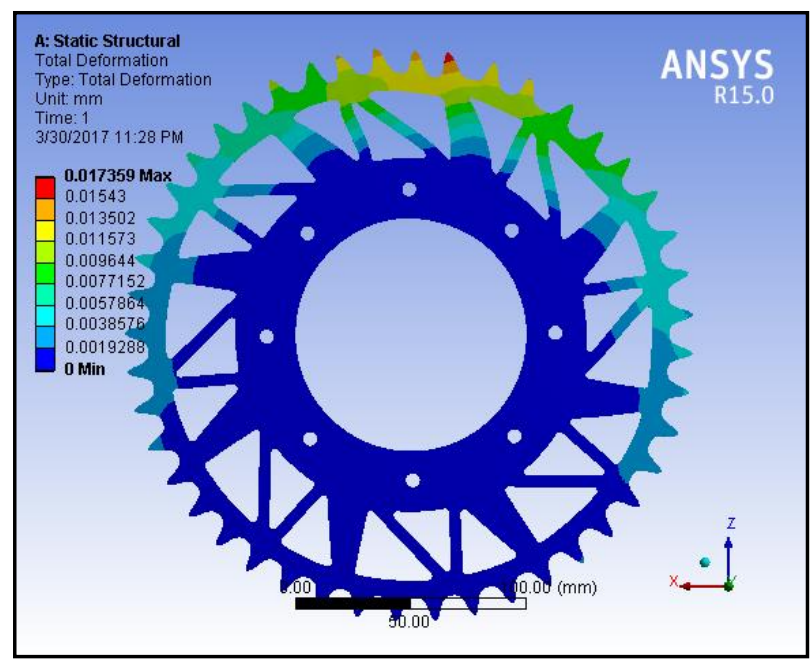

Fig1: Static Structure Analysis

\subsection{Dynamic Analysis}

For a Sprocket, undergoing the extreme forces in Dynamic Conditions is a prime factor. Thus, a Dynamic Analysis validates it, with the following constraints provided-

Maximum Force Applied= 2000N

Maximum Deformation at Dynamic Condition $($ marked by arrow $)=4.90 * 10^{2} \mathrm{~mm}$

Minimum Deformation at Dynamic Condition (Dark Blue Region) $=1.00 * 10^{1} \mathrm{~mm}$.

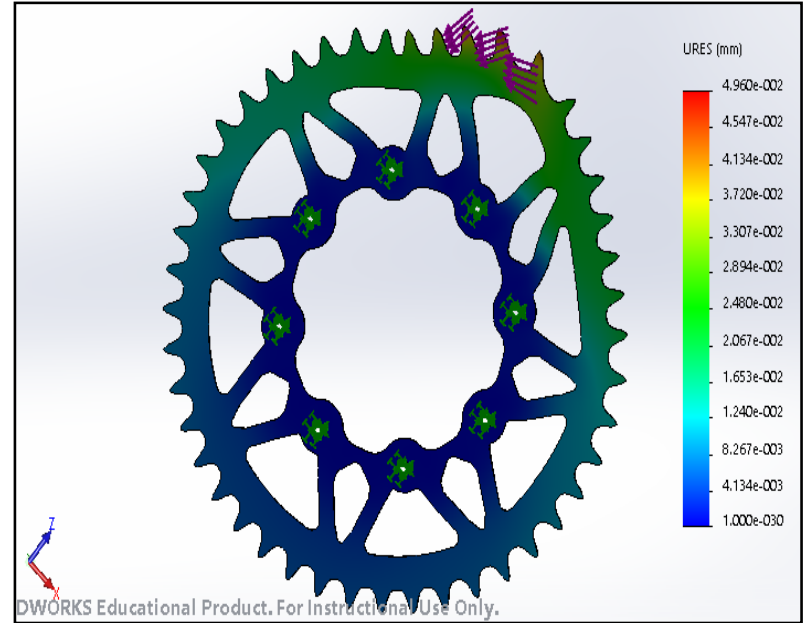

Fig 2: Dynamic Analysis

\subsection{Analysis Results}

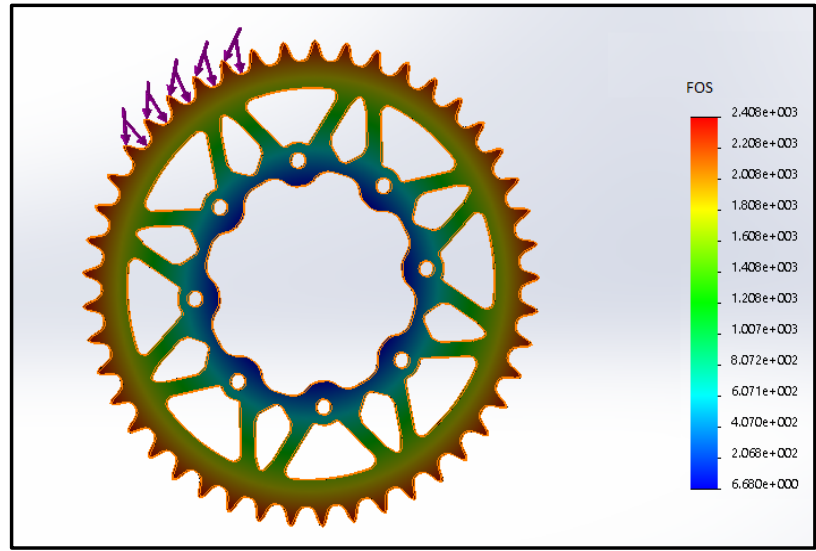

Fig3: Determination Factor of Safety

From the above shown analysis result, the Factor of Safety of the Sprocket can be determined. Thus, the maximum Factor of Safety of the design is 6 while the minimum is 2 . This means that if Double the force taken in context is applied, even then the design failure will not take place and yield point will be achieved once the magnitude of force goes beyond double the value of the force. The Fracture point will be achieved once the force reaches at a magnitude of 6 times greater than the applied force. So, the Factor of Safety is under the limits, as directed by the rules of designing.

\section{F. CONCLUSION}

The CAD modelling of a Sprocket Wheel was done by using DS SolidWorks software. The model was designed, keeping in mind all the rules, required constraints and as per the application in a Formula Student Vehicle. The chain considered for the wheel is that of KTM RC 390 motor-bike, because that is the engine used in the formula student vehicle of which the reference has been taken. Further the analysis of the Sprocket wheel was done using apt CAE software namely ANSYS and DS SolidWorks. Analysis of the wheel was done in terms of Static Structure and under Dynamic Conditions. Factor of Safety of the 
design is under pertained conditions. Thus, this validates the entire design and declares it fit for getting manufactured.

\section{G. REFERENCES}

[1] Documental Repositories, Team Hermes Racing, KIIT University, http://hermesracing.in/index.html.

[2] Machine Design,

www.machinedesign.com/technologies/sprockets-other-halfchain-drive

[3] Design Data Hand Book, S Md. Jalaludeen

\section{H. ABBREVIATIONS USED}

1. $\quad \mathrm{P}=$ Chain Pitch

2. $\quad \mathrm{N}=$ Number of Teeth

3. $\mathrm{D}_{\mathrm{r}}=$ Roller Diameter

4. $\quad \mathrm{D}_{\mathrm{s}}=$ Seating Curve Diameter

5. $\quad \mathrm{R}_{\mathrm{s}}=$ Seating Curve Radius

6. $\quad \mathrm{E}=$ Length of $\operatorname{arc} \mathrm{cy}$

7. $\quad F=$ Radius of complimentary small circle

8. $\quad \mathrm{PD}=$ Pitch Diameter 